Original article

\title{
Transcranial magnetic therapy is an effective strategy for remediating neuroendocrine pathology
}

\author{
Nina V. Bolotova ${ }^{1}$, Andrey P. Averianov ${ }^{1}$, Svetlana V. Timofeeva ${ }^{1}$, Yurii M. Raigorodsky ${ }^{2}$, Olga L. Morova ${ }^{3}$ \\ ${ }^{1}$ Saratov State Medical University n.a. V.I. Razumovsky, Saratov, Russia \\ ${ }^{2}$ TRIMA Ltd, Saratov, Russia \\ ${ }^{3}$ Saratov Socio-Economic Institute of Plekhanov Russian University of Economics, Saratov, Russia
}

Received 26 September 2016, Revised 30 January 2017, Accepted 6 February 2017

C 2016, Bolotova N.V., Averianov A.P., Timofeeva S.V., Raigorodsky Y.M., Morova O.L.

(C) 2016, Russian Open Medical Journal

Abstract: Aspects of reactivation and remediation of impaired functions of the brain and of the inner organs regulatory systems are crucial to medical science. The study presents the technique of transcranial magnetic therapy (TMT) with extremely low frequency alternating magnetic field employed for balanced activation of central nervous system function.

This study was aimed to assess the effectiveness of TMT in diseases caused by hypothalamic-pituitary dysfunction.

Material and Methods - 90 children aged 10-16 years with different diseases but with similar pathogenic patterns were enrolled in the study. Group 1 included 30 adolescent girls with menstrual irregularities. Group 2 included 30 children with nocturnal enuresis. Group 3 included 30 teenage boys with constitutional delay of growth and puberty. Medical histories were studied, clinical and laboratory evaluation was carried out. TMT stimulation was performed using the device "AMO-ATOS" (TRIMA LLC, Saratov, Russia).

Results - Children in all the groups had high incidence of antenatal and perinatal pathologies recorded in their medical histories. Analysis of electroencephalograms (EEG) showed the prevalence of disorganized and flat EEG patterns - $70 \%$ in all the children. Sympathicotonia being the symptom of autonomic nervous system dysfunction, prevailed in $60-80 \%$ of the children. The children in the three groups had hormonal imbalance. The treatment with TMT resulted in considerable improvement in hormonal balance and laboratory findings.

Conclusion - TMT stimulation is effective in remediation of impaired functions of the brain and treatment of the diseases caused by hypothalamic-pituitary dysfunction.

Keywords: hypothalamic-pituitary dysfunction, transcranial magnetic therapy, menstrual irregularities, neurogenic urinary bladder dysfunction, constitutional delay of growth and puberty

Cite as Bolotova NV, Averianov AP, Timofeeva SV, Raigorodsky YM, Morova OL. Transcranial magnetic therapy is an effective strategy for remediating neuroendocrine pathology. Russian Open Medical Journal 2017; 6: e0106.

Correspondence to Nina Bolotova. Address: Department of Propaedeutics of Children's Diseases, Pediatric Endocrinology and Diabetology, Saratov State Medical University n.a. V.I. Razumovsky, 121, Bolshaya Kazachya str., Saratov, 410012, Russia. E-mail: kafedranv@mail.ru

\section{Introduction}

The $20^{\text {th }}$ century saw fundamental advances in neurobiology. Nevertheless, the aspect of balanced activation of central nervous system (CNS) function in man is still of vital importance. Due to this importance, studies of reactivation and remediation of impaired functions of the brain and regulatory systems of inner organs are crucial. Transcranial Magnetic Stimulation (TMS) is a commonly practiced technique of neurostimulation and neuromodulation based on electromagnetic induction of electric field in a specified region of the brain [1]. Since the 1990s, interest in TMS technique has increased dramatically - the number of publications about it has increased as well. According to PubMed there were 67 publications in 1990 and 8699 in 2012 [2]. The majority of these studies were devoted to effectiveness of this technique in treatment of stroke, epilepsy, Parkinson's disease, chronic pain syndromes, etc. [3-5]. Transcranial Direct Current (tDCS) is another technique utilized in clinical practice. It uses direct electrical currents to stimulate specific regions of the brain.
There are two types of stimulation with tDCS: unipolar (mostly, anodal stimulation, which acts to excite neuronal activity) and combined (anodal and cathodal stimulation when two electrodes are placed over the head, which modulates neuronal activity). Thus, different cortical regions that regulate specific functions of the body are under stimulation [6-8]

The technique used in this study is Transcranial Magnetic Therapy (TMT). This technique uses extremely low frequency (ELF) alternating magnetic field (MF) which has neuroremediating, antiinflammatory, and vasodilating therapeutic effect $[9,10]$. Both tDCS and TMT have similar mode of action. However, the use of magnetic field is more favorable as it has few contraindications, and it penetrates deeper into the brain to hypothalamus [9-11]. Data obtained by researchers suggest that CNS, hypothalamus, thalamus, cortex are the most susceptible to TMT [12]. Functional activity of secretory cells of hypothalamus and thalamus is enhanced. TMT has a cerebral vasorelaxant effect and improves cerebral blood flow. Autonomic nervous system is susceptible to 
TMT thus contributing to functional improvement of trophic mechanism of the body $[13,14]$. Stimulation of neuroendocrine system occurs. ELF alternating MF stimulates hypothalamicpituitary axis triggering a chain reaction of peripheral endocrine glands activation and numerous metabolic reactions regulated by these glands [15].

A variety of functions performed by hypothalamic-pituitary axis of thalamencephalon causes different pathologic disturbances including neurologic disorders, endocrine pathologies, autonomic dysfunctions, and emotional imbalance. Hypothalamic region accounts for interaction of psychic, autonomic and emotional spheres $[16,17]$. Due to decompensated regulatory activity of hypothalamic structures, secretion of gonadotropin-releasing hormones $(\mathrm{GnRH})$ and gonadotropins is impaired. Consequently, the synthesis of hormones of peripheral glands is affected. This leads to delayed puberty, menstrual disorders, inappropriate urination, etc.

The aim of the given study was to assess the effectiveness of TMT in diseases caused by hypothalamic-pituitary dysfunction.

\section{Material and Methods \\ Design of the study}

90 children aged 10-16 years with different diseases but with similar pathogenic patterns were enrolled in the study. They were allocated to three groups.

Group 1 included 30 adolescent girls aged 12-16 years with menstrual irregularities: secondary amenorrhea or opsomenorrhea, associated with insulin resistance. The girls' body mass index was high or standard. Criteria for inclusion: menstrual disorder associated with hypothalamic dysfunction accompanied by decreased or imbalanced gonadotropin levels. Criteria for exclusion: a non-classic form of congenital adrenal cortex dysfunction, hyperprolactinemia, syndrome of ovarian polycystosis.

Group 2 included 30 children ( 20 boys and 10 girls) aged 10-15 years with enuresis associated with neurogenic urinary bladder dysfunction. Criteria for inclusion: neurogenic urinary bladder dysfunction caused by the delay in the development of conditioned reflex. Criteria for exclusion: urinary tract infections, abnormal urogenital development, urogenital tumors.

Group 3 included 30 teenage boys with constitutional delay of growth and puberty. Criteria for inclusion: constitutional delay of growth and puberty associated with developmental delay of diencephalic structures formation. Criteria for exclusion: primary and secondary hypogonadism, brain tumors.

The study was approved by Ethics Committee on Research Involving Human Subjects of Saratov State Medical University n.a. V.I. Razumovsky (record №1 from 02 Sep 2014).

\section{Examination techniques}

Anamnesis vitae were studied, measurements of physical growth and development including body height and weight, waist circumference, body mass index (BMI), ideal body weight SDS (standard deviation score), height SDS were taken in all the children. Considering similar pathogenetic patterns of the diseases development in three groups, examination of CNS and autonomic nervous system was also performed apart from a standard examination carried out in case of those diseases.
Table 1. Correlation of indices of baseline BSI and BSI ratio which specifies autonomic reactivity

\begin{tabular}{lccc}
\hline Baseline & & BSI ratio & \\
BSI, cu & Normotonic & Hypersympathicotonic & Asympathicotonic \\
\hline$<30$ & $1.0-3.0$ & $>3.0$ & $<1.0$ \\
$30-60$ & $1.0-2.5$ & $>2.5$ & $<1.0$ \\
$61-90$ & $0.9-1.8$ & $>1.8$ & $<0.9$ \\
$>91$ & $0.7-1.5$ & $>1.5$ & $<0.7$ \\
\hline
\end{tabular}

BSI, Baevskiy's stress index.

Table 2. Criteria for determining ASNC to indicators of power spectrum of periodic components of heart rate in children

\begin{tabular}{lccc}
\hline & $\mathrm{VLF}, \mathrm{ms}^{2}$ & $\mathrm{LF}, \mathrm{ms}^{2}$ & $\mathrm{HF}, \mathrm{ms}^{2}$ \\
\hline Marked ASNC intensity & $\geq 1.33^{*} \mathrm{HF}$ & $\geq 1.33^{*} \mathrm{HF}$ & $\leq 25$ \\
Moderate ASNC intensity & $\geq 0.67 * \mathrm{HF}$ & & $\leq 35$ \\
Normal ASNC intensity & & $35-60$ \\
Moderate ASNC depression & $\leq 0.67 * \mathrm{HF}$ & $\geq 60$ \\
Marked ASNC depression & $\leq 0.33^{*} \mathrm{HF}$ & $\geq 85$ \\
\hline
\end{tabular}

ASNC, activity of subcortical nerve centers.

To evaluate the functional status of CNS, computed electroencephalography (encephalograph "Encephalon-131-01", Medicom MTD Ltd, Taganrog, Rostov region, Russia) was used which was registered in conditions of quiet vigor. Character of alpha-rhythm, presence of dysrhythmia in the frontal, parietal, temporal and occipital leads of the both cerebral hemispheres were detected.

Cardiointervalogram ( $\mathrm{ClG})$ was performed with 5-minutes registration of electrocardiogram in supine rest and 1 minute after orthostasis. CIG was used to perform time-frequency analysis of normal to normal intervals (NN intervals) to assess the status of the autonomic nervous system. The following indices of autonomic control were obtained both in supine and orthostatic positions: standard deviations of NN intervals (SDNN), coefficient of variation $(\mathrm{CV}, \%)$, mode of NN intervals (Mo, s), variation (Var, s; Var $=\mathrm{NN}_{\max }$ - $\mathrm{NN}_{\min }$ ), amplitude of mode (the most frequent value of $\mathrm{NN}$ interval) - number of NN intervals included in the pocket corresponding to mode measured in percentage (AMo, \%), Baevskiy's stress index (BSI, cu; BSI = AMo/(2*Mo*Var)), spectral power of high, low and very low frequency oscillations (HF, LF and VLF, $\mathrm{ms}^{2}$ ) [18].

Assessment of baseline autonomic status was performed using baseline BSI in the following way: eutonia (balanced regulatory function of autonomic nervous system) - BSI is 30-90 cu, vagotonia - BSI is 1-29 cu, moderate sympathicotonia - BSI is 91-160 cu, hypersympathicotonia - baseline BSI is $>160 \mathrm{cu}$ (modified from [18]).

Autonomic reactivity was measured after the patient was positioned vertically. We assessed the ratio of BSI during the first minute of orthostasis to baseline BSI (BSI ratio). According to this results on $\mathrm{BSI}$ ratio, autonomic reactivity was considered as "normotonic", "hypersympathicotonic" and "asympathicotonic" with regard to baseline autonomic status (modified from [18, 19]) (Table 1).

Activity of subcortical nerve centers (ASNC) was determined using the criteria worked out by R.M. Baevsky and O.I. Kirillov [19], which were modified with regard to statistical values of the given study (Table 2). 
Table 3. Urinary urgency perception scale: clinical assessment (based on E.L. Vishnevsky classification [20])

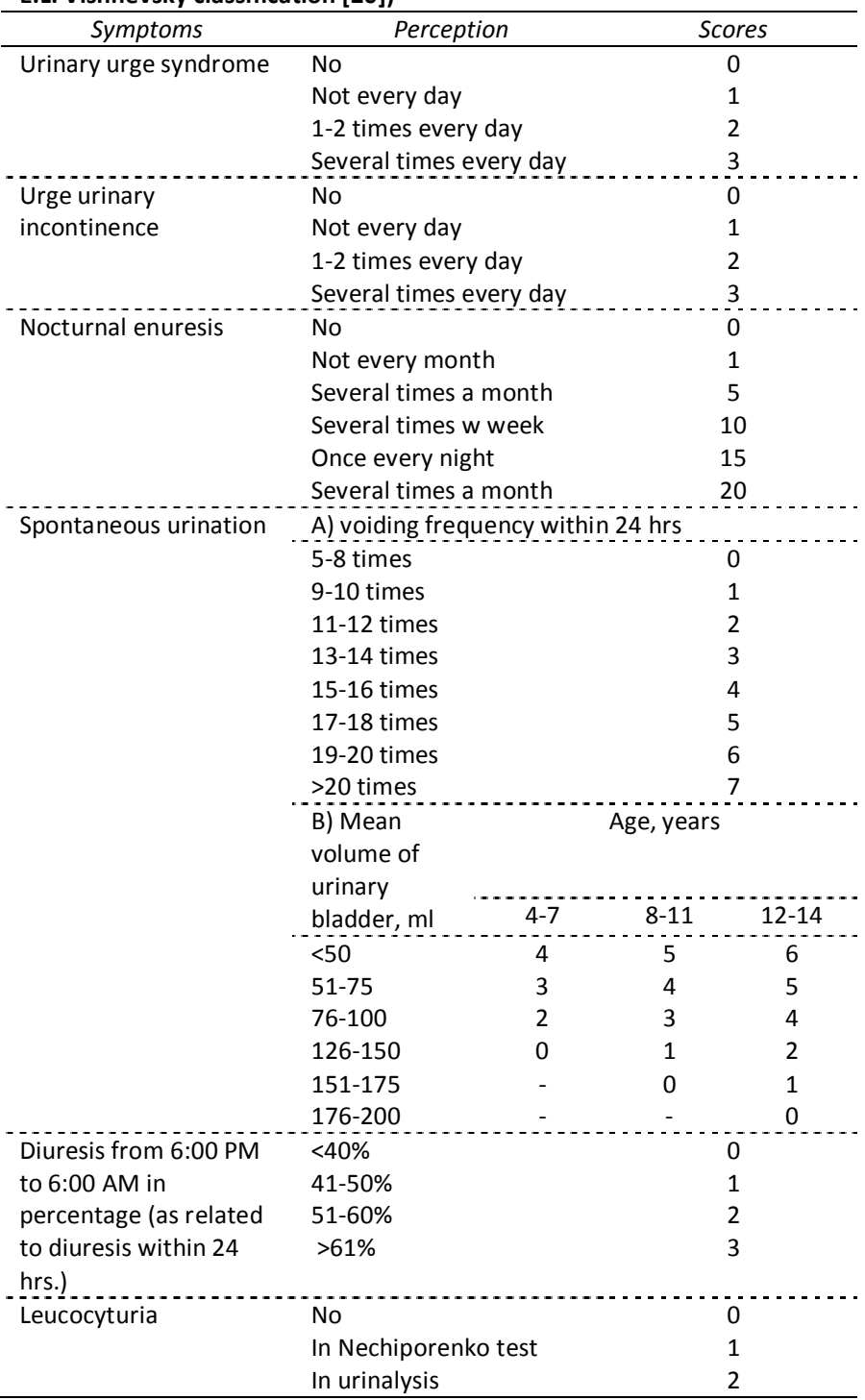

Investigation of hormonal profile was carried out in children with disorders of menstrual cycle and inhibition of pubertal development by means of immunofermental and radioimmune analysis: detection of luteinizing hormone (LH), follicle-stimulating hormone $(\mathrm{FSH})$, estradiol $(\mathrm{E})$, testosterone $(\mathrm{T})$. Immunoreactive insulin (IRI) was studied. For hormonal testing there were applied the immunochemiluminescence method (IMMULITE $2000 \mathrm{Xpi}$ immunoassay system, Siemens, USA) and the immunochemical method (ARCHITECT i2000SR immunoassay analyzer, Abbot Diagnostics, USA).

To characterize clinical signs of imperative urination syndrome in children with enuresis there was used E.L. Vishnevsky's questionnaire evaluating in points the degree of urinary tenesmus, imperative incontinence of urine, pollakiuria, nycturia, reduced average effective volume of the urinary bladder, presence and markedness of leucocyturia. Evaluation within the range of 0-45 points envisaged 3 degrees of severity of imperative urination syndrome - mild (0-10 points), average (11-20) and severe (more than 21 points) [20] (Table 3).
TMT was performed with the help of the device "AMO-ATOS" with the attachment of the "Round-the-head set" (TRIMA Ltd, Saratov, Russia).

In order to evaluate the effectiveness of TMT application the patients of each of the 3 groups were randomly subdivided into two subgroups: basic (A) and control (B). The subgroups $1 \mathrm{~A}$ and $1 \mathrm{~B}$ included 15 girls with menstrual cycle disorders. The subgroups $2 A$ and $2 B$ included 15 children with neurogenic urinary bladder. Each of the subgroups $3 \mathrm{~A}$ and $3 \mathrm{~B}$ included 15 patients with inhibition of growth and puberty.

Patients of subgroup A were administered TMT which was performed with the frequency of magnetic field scanning (modulation) within the range of 1-12 Hz. Sessions were performed with the help of the attachment "Round-the-head set" in the patient's sitting or lying position with the emanator surface induction of $45 \mathrm{mTl}$; the field was moved from the temporal to occipital lobe synchronically onto the both cerebral hemispheres for 7-12 minutes (according to the bitemporal technique). Modulation frequency and exposition period were gradually increased with each procedure, beginning with the minimal parameter. The entire course consisted of 10-15 procedures. Children of subgroup B underwent placebo procedures with switched off magnetic field emanators.

\section{Statistical analysis}

Quantitative indices had abnormal distribution and were presented in the form of a median and intrerquartile range Me (Q1, Q3), qualitative indices - in the form of absolute and relative frequencies (in percents). For evaluation of reliability of differences of quantitative signs between the studied groups of patients Mann-Witney's criterion was used. Differences were considered statistically relevant at $p<0.05$.

\section{Results}

Case histories of all the children were characterized by a high frequency of antenatal and perinatal pathology, such as hypoxic lesion of CNS, presence of hypertensive-hydrocephalic syndrome at the $1^{\text {st }}$ year of life, prematurity (from $60 \%$ to $84 \%$ ).

Analysis of electroencephalograms (EEG) revealed an initially high frequency (70\%) of disorganized and "flat" types, which gave the evidence of brain stem structures' dysfunction, autonomic regulation impairment, prevalence of excitation processes. After treatment, subgroups $A$ were found out to increase EEG total capacity due to $\alpha$-rhythm spectral capacity up to normal values: from $78.5(68.1,88.9)$ to $128(103.5,153.5) \mathrm{mcV}^{2} / \mathrm{Hz}$.

There was observed a distinct positive dynamics in $\alpha$-rhythm differentiation, which registration increased in the subgroup $1 \mathrm{~A}$ by $35 \%$, in the subgroup $2 A-$ by $40 \%$, in the subgroup $3 A-$ by $45 \%$. Dysrhythmia in those groups was reduced by $15 \%$ respectively. At the same time the mean $\alpha$-rhythm frequency in A subgroups increased from $7.5(6.3,8.7)$ to $13.2(12.1,14.3) \mathrm{Hz}$. Thus, it may be supposed that TMT with the scanning frequency of $10 \mathrm{~Hz}$ organized the basic EEG rhythm imposing it upon the brain structures. The analysis of data before and after treatment in $B$ subgroups did not reveal any reliable differences in EEG parameters (Table 4). 
Table 4. Frequency and amplitude of $\alpha$-rhythm in EEG of children before and after treatment

\begin{tabular}{|c|c|c|c|c|c|c|c|c|c|c|c|c|}
\hline \multirow{3}{*}{ Parameters } & \multicolumn{6}{|c|}{ Basic subgroup A $(n=45)$} & \multicolumn{6}{|c|}{ Control subgroup $B(n=45)$} \\
\hline & \multicolumn{3}{|c|}{ Before treatment } & \multicolumn{3}{|c|}{ After treatment } & \multicolumn{3}{|c|}{ Before treatment } & \multicolumn{3}{|c|}{ After treatment } \\
\hline & $1 \mathrm{~A}$ & $2 \mathrm{~A}$ & $3 \mathrm{~A}$ & $1 \mathrm{~A}$ & $2 \mathrm{~A}$ & $3 \mathrm{~A}$ & $1 \mathrm{~B}$ & $2 \mathrm{~B}$ & $3 B$ & $1 \mathrm{~B}$ & $2 B$ & $3 B$ \\
\hline \multicolumn{13}{|c|}{$\alpha$-rhythm frequency } \\
\hline $\mathrm{Rr}$ & $2(13 \%)$ & $4(27 \%)$ & $2(13 \%)$ & $3(20 \%)$ & $3(20 \%)$ & $2(13 \%)$ & $4(27 \%)$ & $4(27 \%)$ & $2(13 \%)$ & $4(27 \%)$ & $4(27 \%)$ & $4(27 \%)$ \\
\hline $\mathrm{Nr}$ & $4(27 \%)$ & $6(40 \%)$ & $3(20 \%)$ & $9(60 \%)^{*}$ & $10(67 \%)^{*}$ & $11(73 \%)^{*}$ & $3(20 \%)$ & $5(33 \%)$ & $4(27 \%)$ & $3(20 \%)$ & $6(40 \%)$ & $5(33 \%)$ \\
\hline Ar. & $9(60 \%)$ & $5(33 \%)$ & $10(67 \%)$ & $3(20 \%)$ & $2(13 \%)$ & $2(13 \%)$ & $8(53)$ & $6(40 \%)$ & $9(60 \%)$ & $8(53 \%)$ & $5(33 \%)$ & $6(40 \%)$ \\
\hline "Flat" & & & & & & & & & & & & \\
\hline Flat & ব(53\%) & $8(53 \%)$ & $10(6 / \%)$ & $\perp(/ \%)$ & $\perp(/ \%)$ & $1(1 \%)$ & $/(4 / \%)$ & $6(40 \%$ & 8153 & $3(20 \%)$ & $3(20 \%)$ & $3(20$ \\
\hline Low & $2(13 \%)$ & $2(13 \%)$ & $2(13 \%)$ & $2(13 \%)$ & $2(13 \%)$ & $1(7 \%)$ & $5(33 \%)$ & $5(33 \%)$ & $3(20 \%)$ & $6(40 \%)$ & $4(27 \%)$ & $3(20 \%)$ \\
\hline Normal & $2(13 \%)$ & $2(13 \%)$ & $1(7 \%)$ & $9(60 \%)^{*}$ & $10(67 \%)^{*}$ & $12(80 \%)^{*}$ & $2(13 \%)$ & $2(13 \%)$ & $2(13 \%)$ & $3(20 \%)$ & $4(27 \%)$ & $4(27 \%)$ \\
\hline
\end{tabular}

$\mathrm{Rr}$, Reduced rhythm ( $\leq 8 \mathrm{~Hz}) ; \mathrm{Nr}$, Normal rhythm $(9-12 \mathrm{~Hz}) ; \mathrm{Ar}$, Accelerated rhythm ( $\geq 13 \mathrm{~Hz}$ ); EEG, electroencephalogram. Amplitudes of EEG: "flat" is $\leq 25$ $\mathrm{mcV}$, low is $26-50 \mathrm{mcV}$, normal is $51-100 \mathrm{mcV}$. Data presented as absolute and relative frequencies - no. (\%). * - reliable differences with a corresponding parameter before treatment $(p<0.05)$.

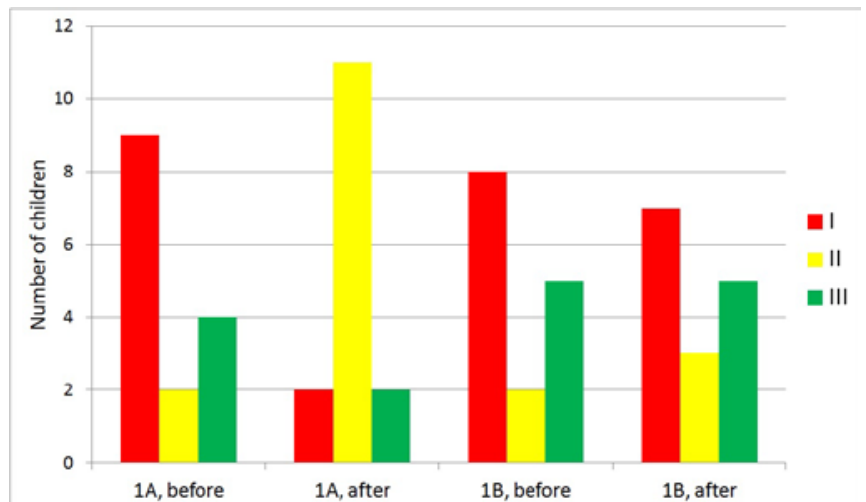

Figure 1. Distribution of the children of Group 1 according to the types of autonomic status (I - sympathicotonia; II - eutonia; III - vagotonia) before and after treatment.

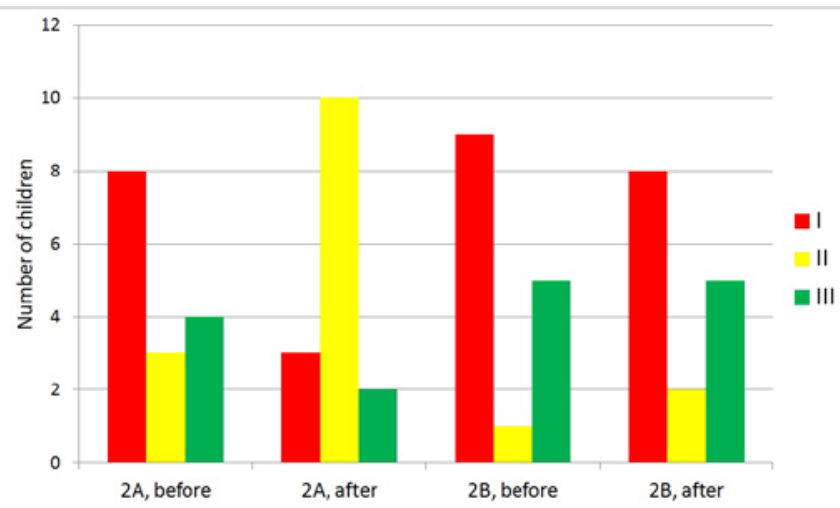

Figure 2. Distribution of the children of Group 2 according to the types of autonomic status (I - sympathicotonia; II - eutonia; III - vagotonia) before and after treatment.

According to the results of cardiointervalography it was established that at the background of the performed TMT the autonomic status improved (Figures 1-3). So, if before treatment sympathicotonia prevailed in the autonomic status $(68 \%$ in all 3 groups), after treatment the number of children with eutonia was reliably increased in $1 \mathrm{~A}$ subgroup by 4.5 times $(p<0.05)$, in $2 \mathrm{~A}$ and $3 A$ subgroups - by 3.3 times $(p<0.05)$. In $B$ subgroups no changes in the autonomic status after treatment were registered.

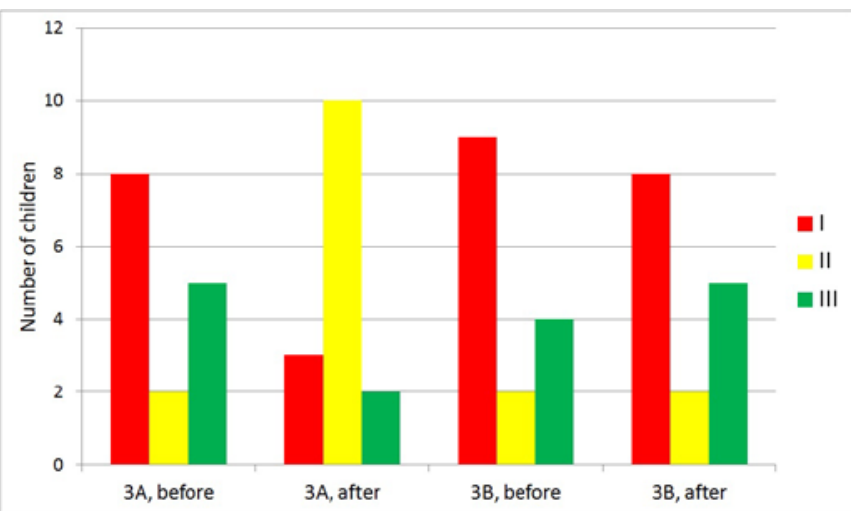

Figure 3. Distribution of the children of Group 3 according to the types of autonomic status (I - sympathicotonia; II - eutonia; III - vagotonia) before and after treatment.

Out of the total number of the initially examined children only $22 \%$ of the patients had normal ASNC and in $78 \%$ of the patients it was intensified. After treatment in A subgroups the number of children with normal ASNC increased from 16 to 52 (by 50\%), while in $B$ subgroups it became unchanged.

In female teenagers at the background of the carried out TMT there were observed the increase of FSH and LH levels, normalization of estrogen and testosterone levels, as well as the decrease of IRI level (Table 5).

In $60 \%$ of the girls-teenagers normalization of hormonal indices was accompanied by restoration of the menstrual cycle, in part of the children (20\%) - after performance of 2-3 courses of TMT with the interval of 2 months.

Clinically inhibition of growth and puberty in the children of Group 3 was manifested by the lack of secondary sexual characters, reduced growth SDS $\{-2.25(-2.75,-1.75)\}$, as well as by a change of the hormonal background (Table 6$)$.

It is seen from Table 6 that after treatment with TMT there was observed the increase of total testosterone, LH, FSH levels, which was accompanied by initiation of puberty within 3 months. In boys of $3 B$ subgroup the average level of sexual hormones corresponded to prepubertal values.

In most children of Group 2 (60\%) dysfunction of the urinary bladder was marked since early age and it was qualified as primary enuresis, in the rest of the children - as acquired enuresis with one year and longer case history. 
Table 5. Indices of hormonal status in children of Group 1 before and after treatment with TMT

\begin{tabular}{|c|c|c|c|c|}
\hline \multirow[t]{2}{*}{ Parameters } & \multicolumn{2}{|c|}{ Subgroup 1A $(n=15)$} & \multicolumn{2}{|c|}{ Subgroup 1B $(n=15)$} \\
\hline & Before treatment & After treatment & Before treatment & After treatment \\
\hline $\mathrm{FSH}, \mathrm{IU} / \mathrm{I}$ & $4.3(3.2,5.4)$ & $5.8(5.1,6.5)^{*}$ & $5.2(3.8,6.6)$ & $5.5(3.5,7.7)$ \\
\hline $\mathrm{LH}, \mathrm{IU} / \mathrm{I}$ & $3.8(3.2,4.4)$ & $6.5(4.3,8.7)^{*}$ & $5.2(2.6,7.8)$ & $5.3(1.6,9.0)$ \\
\hline Estradiol, pmol/l & $660.0(605.2,715.6)$ & $992.0(902.2,1083.2)^{*}$ & $950.7(858.2,1043.2)$ & $966.7(871,1062.4)$ \\
\hline Testosteron, $\mathrm{nmol} / \mathrm{l}$ & $1.6(1.2,3.0)$ & $2.5(0.5,4.5)^{*}$ & $2.6(0.4,4.8)$ & $2.5(1.0,4.0)$ \\
\hline IRI, mcUnits/ml & $30.6(23.1,38.1)$ & $21.6(19.4,23.8)^{*}$ & $28.6(21.4,35.8)$ & $25.9(16.4,35.4)$ \\
\hline
\end{tabular}

FSH, follicle-stimulating hormone; LH, luteinizing hormone; IRI, immunoreactive insulin. ${ }^{*}$ - reliable differences with a corresponding parameter before treatment $(p<0.05)$.

Table 6. Dynamics of the results of hormonal examination of Group 3 children before and after treatment with TMT

\begin{tabular}{|c|c|c|c|c|}
\hline \multirow{2}{*}{ Parameters } & \multicolumn{2}{|c|}{ Subgroup $3 A(n=15)$} & \multicolumn{2}{|c|}{ Subgroup $3 B(n=15)$} \\
\hline & Before treatment & After treatment & Before treatment & After treatment \\
\hline Testosteron, $\mathrm{nmol} / \mathrm{I}$ & $1.2(0.9,1.5)$ & $7.1(5.4,7.8)^{*}$ & $1.4(1.2,1.6)$ & $1.2(0.9,1.5)$ \\
\hline LH, IU/I & $1.1(0.8,1.4)$ & $2.5(1.0,4.0)^{*}$ & $1.2(0.9,1.5)$ & $1.3(1.1,1.5)$ \\
\hline $\mathrm{FSH}, \mathrm{IU} / \mathrm{I}$ & $1.6(1.4,1.8)$ & $4.7(3.5,5.9)^{*}$ & $1.5(1.3,2.5)$ & $1.7(1.5,1.9)$ \\
\hline
\end{tabular}

$\mathrm{LH}$, luteinizing hormone; FSH, follicle-stimulating hormone. ${ }^{*}$ - reliable differences with a corresponding parameter before treatment $(p<0.05)$.

Table 7. Dynamics of distribution of the patients according to the degree of severity of imperative urination syndrome (in points, according to E.L. Vishnevsky)

\begin{tabular}{lccc}
\multicolumn{1}{c}{ Degree of severity } & Subgroup 2A $(n=15)$ & Subgroup 2B (n=15) & \\
\hline Normal & Before treatment & After treatment & After treatment \\
Mild (1-10 points) & - & $10(67 \%)^{*}$ & - \\
Average (11-20 points) & $8(53 \%)$ & $4(27 \%)^{*}$ & $4(27 \%)$ \\
Severe ( $\geq 21$ points) & $4(27 \%)$ & $1(7 \%)$ & $10 \%)$ \\
\hline
\end{tabular}

Data presented as absolute and relative frequencies - no. $(\%){ }^{*}-$ reliable differences with control $(p<0.05)$

It is seen from the data of Table 7 that after treatment all the patients were marked to show positive dynamics in the clinical picture, which was characterized by reduced imperative urinary tenesmus. Besides, evaluation of the subgroup $2 \mathrm{~A}$ in points significantly surpassed the corresponding values in the subgroup 2B. Upon completing the treatment, the acuity of clinical symptomatic in the subgroup of children treated with TMT reduced by 13 points (70\%); in the subgroup of children treated with placebo procedures no changed were revealed.

\section{Discussion}

Hypothalamic-pituitary axis dysregulation results in reproductive system dysfunction, inappropriate urination, stress disorder, etc. Three groups of teenagers with different pathologies entered the study. The key element in the pathogenesis of these pathologies was hypothalamic-pituitary dysfunction. Group 1 included 30 adolescent girls aged 12-16 with menstrual irregularities: secondary amenorrhea or opsomenorrhea. The menstrual cycle requires precise coordination between several processes in the body. Menstrual cyclicity and timely ovulation are the result of precise integration of a series of events occurring within the different components of the reproductive system. CNS regulates hypothalamic-pituitary-ovarian axis ensuring sustainable functioning of reproductive system.

Children with neurogenic urinary bladder dysfunction were enrolled in Group 2. Voiding disorders were observed in these children. These disorders were related to neurological damage caused by different conditions. In case the patients did not have urinary infections, the disorders were attributed to abnormalities that interfere with the growth of the cerebral cortex [21]. Group 3 included teenage boys with constitutional delay of growth and puberty caused by hypothalamic-pituitary-gonadal axis dysfunction. Delayed puberty is often associated with the absence or incomplete development of secondary sexual characteristics bounded by the age of 14 and can be caused by a variety of hypothalamic, pituitary, and gonadal disorders. It affects bone mineral density, final height, and personality development. Thus, all the three groups of diseases have similar pathogenic patterns caused by hypothalamic-pituitary dysfunction. Therefore, transcranial techniques, TMT including, can be effective in remediation of impaired functions of the brain and treatment of the diseases.

It has been scientifically proven that transcranial stimulation techniques used to improve impaired functions of the brain are effective because they stimulate excitable tissue with an electric current induced by an external time-varying magnetic field. The magnetic field penetrates unattenuated and induces electrical activity in the underlying brain tissue. Magnetic field has neuroremediating, anti-inflammatory, and vasodilating therapeutic effect. Noninvasive magnetic control over neuronal activity has been validated [22].

Influences of TMT with alternating magnetic field, which scan rate is $1-12 \mathrm{~Hz}$ ( $\alpha$-rhythm frequency in normal EEG) occur at the hypothalamic level. Magnocellular neurons in the anterior hypothalamus influence the secretion of the releasing factors. Magnetic control of hypothalamus regulates immune and endocrine systems and exposure to low-frequency alternating magnetic field with scan rate $1-12 \mathrm{~Hz}$ enhances biological and electrical activities of hypothalamus [23, 24].

Evidence suggests the effectiveness of TMT in different areas of medicine. The present study provides another evidence of TMT positive effect and ascertains the effectiveness of exposure to extremely low frequency alternating magnetic field. The study also 
supports the magnetic stimulation techniques developed by Russian researchers $[25,26]$.

\section{Conclusion}

The results of the present study indicate that changes in biological and electrical activities of the brain and disorders of autonomic nervous system in children with different diseases have similar pathogenic patterns caused by hypothalamic-pituitary dysfunction. Exposure to extremely low frequency alternating magnetic field can be effective in remediation of impaired functions of the brain and treatment of the diseases. TMT application can be regarded as a new and effective strategy as it has immediate and prolonged neurobiological effects.

\section{Limitations}

Although there is much remains to be done, our study generates important findings in the field of TMT. We can nevertheless confirm that there is a limitation of this study. The limitation is that patients with a non-classic form of congenital adrenal cortex dysfunction, hyperprolactinemia, syndrome of ovarian polycystosis, urinary tract infections, abnormal urogenitaldevelopment, urogenital tumorsprimary and secondary hypogonadism, brain tumorswere not considered.

This study provides evidence that exposure to extremely low frequency alternating magnetic field can be effective in remediation of impaired functions of the brain and treatment of the diseases. Further research in this area is planned to confirm the effectiveness of TMT. Moreover, immune status in patients with the diseases caused by hypothalamic-pituitary dysfunction is going to be studied as well as the possibility of TMT to improve it.

We used a rather crude assessment of autonomic control. In future studies, it is appropriate to use modern methods for autonomic control assessment $[27,28]$

\section{Conflict of interest: none declared.}

\section{References}

1. Belova AN, Baldova SN. Transcranial magnetic stimulation: clinical applications and research potential. Advances in Current Natural Sciences 2015; 9(1): 34-42. Russian https://www.naturalsciences.ru/en/article/view?id=35521.

2. Classen J. Transcranial magnetic stimulation. Practical Sessions/Handon courses 1. In: Proceeding of EFNS Congress, Istanbul, Turkey, 2014. https://www.ean.org/fileadmin/ migrated/content uploads/PrSe1 0 1 Classen.pdf

3. Elahi B, Elahi B, Chen R. Effect of transcranial magnetic stimulation on Parkinson motor function - systematic review of controlled clinical trials. Mov Disord 2009; 24(3): 357-363. https://dx.doi.org/10.1002/mds.22364.

4. Couturier JL. Efficacy of rapid-rate repetitive transcranial magnetic stimulation in the treatment of depression: a systematic review and meta-analysis. J Psychiatry Neurosci 2005; 30: 83-90. https://www.ncbi.nlm.nih.gov/pmc/articles/PMC551158/

5. Bae EH, Schrader LM, Machii K, Alonso-Alonso M, Riviello JJ Jr, PascualLeone A, Rotenberg A. Safety and tolerability of repetitive transcranial magnetic stimulation in patients with epilepsy: a review of the literature. Epilepsy Behav 2007; 10: 521-528. https://dx.doi.org/10.1016/i.yebeh.2007.03.004.

6. Motto C, Tamma F, Candelise L, Pecoraro V, Banzi R, Moja L. Deep brain stimulation of subthalamic nucleus for Parkinson's disease
(Protocol). Cochrane Database of Systematic Reviews 2016; (7). https://dx.doi.org/10.1002/14651858.CD004491.pub2.

7. Morin A, Guillaume L, Gougeon V, Waddell G, Bureau YA, Girard I, Morin M. Efficacy of transcranial direct-current stimulation (tDCS) in women with provoked vestibulodynia: study protocol for a randomized controlled trial. Trials 2016; 17(1): 243. https://dx.doi.org/10.1186\%2Fs13063-016-1366-5.

8. Elsner B, Kugler J, Pohl M, Mehrholz J. Transcranial direct current stimulation for improving idiopathic Parkinson's syndrome. An abridged version of a Cochrane review. Eur J Phys Rehabil Med 2016; 52(6): 902-906. https://www.ncbi.nlm.nih.gov/pubmed/27701368.

9. Capone F, Dileone M, Profice P, Pilato F, Musumeci G, Minicuci G, et al. Does exposure to extremely low frequency magnetic fields produce functional changes in human brain? J Neural Transm 2009; 116(3): 257-265. https://dx.doi.org/10.1007/s00702-009-0184-2.

10. Plekhanov GF. On the perception of a man insensible signals. PhD thesis. Tomsk, Russia, 1967; 22 p. Russian

11. Legros A, Gaillot P, Beuter A. Transient effect of low-intensity magnetic field on human motor control. Med Eng Phys 2006; 28(8): 827-836. https://dx.doi.org/10.1016/j.medengphy.2005.11.003.

12. Demetsky AM, Chernov VN, Popova LN. Introduction to medical magnetism. Rostov-on-Don, Russia, 1991; 135 p. Russian

13. Manukian Vlu, Bolotova NV, Aver'ianov AP, Filina Nlu, Raĭgorodski luM. Autonomic dysfunction syndrome and diabetic cardiac autonomic neuropathy in children with diabetes mellitus type I. The correction method. Zh Nevrol Psikhiatr Im S S Korsakova 2011; 111(1): 33-37. Russian https://www.ncbi.nlm.nih.gov/pubmed/21350409.

14. Khan MA, Boltneva SM. Magnetic therapy in a complex treatment of children with perinatal lesions of the central nervous system. Russian Journal of Pediatrics 2003; (3): 7-10. Russian

15. Konkov AF, Shehaeva OM, Usachev MD. Effect of static magnetic field on the state simpatoadrenalovoj systems of the body in plastic opreatsii on the face and neck. In: Topical issues of magneto and magneto: Conference proceedings. Izhevsk, Russia, 1981: 169. Russian

16. Ponomarenko GN. Physiotherapy: national leadership. Moscow, Russia: GEOTAR Media, 2015; 600 p. Russian

17. Ponomarenko GN, Bolotova NV, Raigorodskii YM. Transcranial magnetic. SPb., Russia: Man, 2016. Russian

18. Baevskiy RM, Ivanov GG. Heart rate variability: theoretical aspects and possibilities of clinical application. Ultrazvukovaya $i$ Funktsionalnaya Diagnostika 2001; (3): 106-127. Russian

19. Baevsky RM, Kirillov OI, Kletskin SZ. Mathematical analysis of heart rate changes during stress. Moscow, Russia: Nauka, 1984; 221 p. Russian

20. Vishnevsky EL. Overactive bladder syndrome in children. Problems of Modern Pediatrics 2007; 6(2): 63-70. Russian

21. Shulga A, Zubareva A, Lioumis P, Makela JP. Paired associative stimulation with high-frequency peripheral component leads to enhancement of corticospinal transmission at wide range of interstimulus intervals. Front Hum Neurosci 2016; 10: 470. https://dx.doi.org/10.3389\%2Ffnhum.2016.00470.

22. Shiozawa P, Gomes JS, Ducos DV, Akiba HT, Dias ÁM, Trevizol AP, et al. Effect of transcranial direct current stimulation (tDCS) over the prefrontal cortex combined with cognitive training for treating schizophrenia: a sham-controlled randomized clinical trial. Trends Psychiatry Psychother 2016; 38(3): 175-177. https://dx.doi.org/10.1590/2237-6089-2015-0043.

23. Hu X-S, Fisher CA, Munz SM, Toback RL, Nascimento TD, Bellile EL, et al. Feasibility of non-invasive brain modulation for management of pain related to chemoradiotherapy in patients with advanced head and neck cancer. Front Hum Neurosci 2016; 10: 466. https://dx.doi.org/10.3389/fnhum.2016.00466.

24. Di Lazzaro V, Capone F, Apollonio F, Borea PA, Cadossi R, Fassina L, et al. A consensus panel review of central nervous system effects of the exposure to low-intensity extremely low-frequency magnetic fields. 

Brain
Stimul
2013;
6(4):
469-476.

https://dx.doi.org/10.1016/j.brs.2013.01.004

25. Orekhova EM, Svistunov AA, Konchugova TV, Prikazchikova OA, Răgorodskĭ luM. Efficacy of dynamic magnetic therapy in the complex treatment of cognitive disturbances in patients with chronic cerebrovascular insufficiency. Zh Nevrol Psikhiatr Im S S Korsakova 2009; 109(2): 59-62. Russian https://www.ncbi.nlm.nih.gov/pubmed/19385120.

26. Bolotova NV, Averyanov AP, Dronova EG, Raigorodskii YuM, Posokhova NV. Non-drug correction of neuroendocrine disorders in puberty girls with obesity. Obstetrics and Gynecology 2012; (7): 92-97. Russian http://www.aig-journal.ru/en/archive/article/11218.

27. Kiselev AR, Karavaev AS, Gridnev VI, Prokhorov MD, Ponomarenko VI, Borovkova El, et al. Method of estimation of synchronization strength between low-frequency oscillations in heart rate variability and photoplethysmographic waveform variability. Russian Open Medical Journal 2016; 5: e0101. https://dx.doi.org/10.15275/rusomj.2016.0101.

28. Kiselev AR, Mironov SA, Karavaev AS, Kulminskiy DD, Skazkina VV, Borovkova El, et al. A comprehensive assessment of cardiovascular autonomic control using photoplethysmograms recorded from the earlobe and fingers. Physiol Meas 2016; 37: 580-595. https://dx.doi.org/10.1088/0967-3334/37/4/580.

Authors:

Nina V. Bolotova - MD, D.Sc., Professor, Department of Propaedeutics of Children's Diseases, Pediatric Endocrinology and Diabetology, Saratov State Medical University n.a. V.I. Razumovsky, Saratov, Russia. http://orcid.org/0000-0002-8148-526X.

Andrey P. Averianov - MD, D.Sc., Professor, Department of Propaedeutics of Children's Diseases, Pediatric Endocrinology and Diabetology, Saratov State Medical University n.a. V.I. Razumovsky, Saratov, Russia. http://orcid.org/0000-0002-0341-3199.

Svetlana V. Timofeeva - MD, PhD, Assistent, Department of Propaedeutics of Children's Diseases, Pediatric Endocrinology and Diabetology, Saratov State Medical University n.a. V.I. Razumovsky, Saratov, Russia.

Yurii M. Raigorodsky - PhD, Director of TRIMA Ltd, Saratov, Russia.

Olga L. Morova - PhD, Associate Professor, Department of Translation Theory and Intercultural Communication, Saratov Socio-Economic Institute of Plekhanov Russian University of Economics, Saratov, Russia. 